\title{
BMJ Open Decreasing referrals to transient ischaemic attack clinics during the COVID-19 outbreak: results from a multicentre cross-sectional survey
}

\author{
Lucio D'Anna (D) , ${ }^{1,2}$ Ambreen Sheikh, ${ }^{3}$ Raj Bathula, ${ }^{4}$ Salwa Elmamoun, ${ }^{5}$ \\ Adelaide Oppong, ${ }^{5}$ Ravneeta Singh, ${ }^{5}$ Rebecca Redwood, ${ }^{5}$ John Janssen, ${ }^{5}$ \\ Soma Banerjee, ${ }^{1,2}$ Evangelos Vasileiadis ${ }^{6}$
}

To cite: D'Anna L, Sheikh A, Bathula $\mathrm{R}$, et al. Decreasing referrals to transient ischaemic attack clinics during the COVID-19 outbreak: results from a multicentre crosssectional survey. BMJ Open 2020;10:e041514. doi:10.1136/ bmjopen-2020-041514

- Prepublication history for this paper is available online. To view these files, please visit the journal online (http://dx.doi. org/10.1136/bmjopen-2020041514).

Received 10 June 2020 Revised 29 August 2020 Accepted 05 0ctober 2020
Check for updates

(c) Author(s) (or their employer(s)) 2020. Re-use permitted under CC BY-NC. No commercial re-use. See rights and permissions. Published by BMJ.

For numbered affiliations see end of article.

Correspondence to

Dr Lucio D'Anna;

I.danna@imperial.ac.uk

\section{ABSTRACT}

Objective The COVID-19 pandemic is having major implications for stroke care with a documented significant fall in hospital acute stroke admissions. We investigated whether COVID-19 has resulted in a decreased number of referrals to the transient ischaemic attack (TIA) clinics across the North West London region.

Setting and design All the TIA clinical leads of the North West London region received an invitation by email to participate in an online survey in May 2020. The survey questionnaire aimed to assess the number of patients with suspected TIA consecutively referred to each of the TIA clinics of the North West London region between 1 March and 30 April 2020, the COVID-19 period, and between 1 March and 30 April 2019.

Results We had a response rate of $100 \%$. During the COVID-19 period, the TIA clinics of the North West London region received 440 referrals compared with 616 referrals received between 1 March and 30 April 2019 with a fall in the number of the referrals by $28.6 \%$. In April 2020 compared with April 2019, the number of the referrals declined by $40.1 \%$.

Conclusions This multicentre analysis documented a significant reduction in the number of patients referred with suspected TIA to the specialised rapid access outpatient clinics in the North West London region during the COVID-19 pandemic. Future studies are needed to confirm our findings and to better characterise the incidence of cerebrovascular disease during the COVID-19 pandemic.

\section{INTRODUCTION}

Transient ischaemic attack (TIA) is a common neurological emergency that is strongly associated with a high early risk of subsequent stroke. Therefore, urgent assessment and management of patients in a dedicated TIA clinic is considered to be critical to reduce significantly the 90-day stroke risk by almost $80 \% .^{1-4}$ Recent evidence showed that the number of patients attending the emergency department (ED) has significantly decreased ${ }^{5}$ during the COVID-19 pandemic because of
Strengths and limitations of this study

- This is the first study investigating the effects of COVID-19 on the volume of patients presenting to transient ischaemic attack clinics rather stroke units during the COVID-19 pandemic.

- Response rate of $100 \%$.

- Reflection of results within the National Health Service in North West London region that might not be generalised to all international healthcare practices.

fear of contracting the infection. ${ }^{6}$ In addition, the rate of non-respiratory hospital admissions for conditions such as acute coronary syndrome sharply fell. ${ }^{7}$ These observations suggested that some patients could have delayed the care for such conditions or died without seeking medical attention during the COVID-19 pandemic.

A recent survey of the World Stroke Organisation across multiple countries including UK, Italy, Belgium, Greece, Iran, Chile and Colombia has documented that the COVID-19 pandemic has affected stroke care with a significant fall in the number of stroke admissions, up to $80 \%$, during the COVID-19 outbreak. ${ }^{8}$ Moreover, preliminary data suggested that a smaller proportion of patients with milder stroke symptoms presented to hospital during the COVID-19 pandemic. ${ }^{9}$ However, to date, it is unclear if COVID-19 pandemic has impacted on the number of referrals to the TIA clinics. In this observational multicentre survey, we compared the number of patients with suspected TIA referred to all the TIA clinics across the North West London region during the COVID-19 pandemic compared with a similar period in 2019. 


\section{NORTH WEST LONDON REGION}

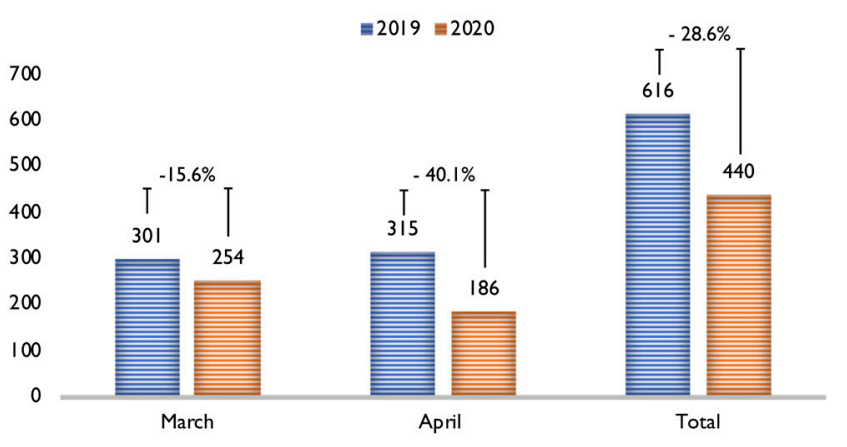

Figure 1 Numbers of patients with suspect of transient ischaemic attack (TIA) referred overall to the TIA clinics of North West London region between 1 March to 30 April 2020 and 1 March to 30 April 2019.

\section{METHODS}

We conducted a multicentre, cross-sectional survey in May 2020 to assess the impact of the current COVID-19 pandemic on the number of patients with suspected TIA referred to all the TIA clinics across the North West London region using a standard questionnaire. The population of the North West London region includes 2.4 million residents. This region includes five stroke centres with dedicated specialist TIA outpatient clinics based at the Charing Cross Hospital, Chelsea and Westminster Hospital, Hillingdon Hospital, Northwick Park Hospital and West Middlesex Hospital. In these centres almost all stroke and TIA patients are referred to by local general practitioners (GPs) in the primary-care or EDs. The referral pathway of patients with suspected TIA was unchanged in 2020 compared with 2019. The questionnaire was sent to all National Health Service TIA clinical leads in the North West London region. The survey that was sent to all the five TIA clinical leads asked the following questions: (1) what is the number of patients with suspected TIA referred to your TIA clinic service between 1 and 31 March 2019?; (2) what is the number of patients with suspected TIA referred to your TIA clinic service between 1 and 31 March 2020?; (3) what is the number of patients with suspected TIA referred to your
TIA clinic service between 1 and 30 April 2019?; (4) what is the number of patients with suspected TIA referred to your TIA clinic service between 1 and 30 April 2020? The primary outcome measures of our survey questionnaire were the number of patients with suspected TIA consecutively referred to each of the TIA services of the North West London region between 1 March and 30 April 2020, the COVID-19 period, and between 1 March and 30 April 2019. Each TIA clinical lead was asked to provide the number of TIA referrals received in March and April 2019 and in March and April 2020. The selected start date was 1 March 2020 of the COVID-19 period as the first case was documented in UK on 28 February. Each TIA clinical lead provided data on consecutive eligible patients referred to their service by using a databank of admissions that is used for reporting to a central UK stroke data bank Sentinel Stroke National Audit Programme. Electronic and paper based medical records of eligible patients were retrieved from each hospital medical archive. This survey was carried out using data collected as part of routine care and any researchers outside of the direct care team only had access to anonymised data. All the TIA clinical leads received a prenotification letter that described the study and requested their participation. One week later, a second contact included a cover letter describing the study, assuring confidentiality and providing instructions for completion of the survey and the survey instrument. In total, one reminder was sent to all the TIA clinical leads. No incentives were provided. We had a response rate of $100 \%$. All data were entered into an electronic Excel database (Microsoft Corp, Redmond, Wash). Single data entry was used. Descriptive results are presented as percentage using Excel.

\section{Patient and public involvement}

No patient involved.

\section{RESULTS}

Figure 1 and table 1 show the overall number of consecutive patients with suspected TIA referred to the TIA services of the North West London region and the number of referrals received by each TIA centre between

Table 1 Numbers of patients with suspect of transient ischaemic attack (TIA) referred each of the TIA clinics of North West London region between 1 March to 30 April 2020 and 1 March to 30 April 2019

\begin{tabular}{lccccc}
\hline & Charing Cross Hospital & Chelsea and Westminster Hospital & Hillingdon Hospital & Northwick Park Hospital & West Middlesex Hospital \\
\hline March 2019 $(n)$ & 83 & 21 & 15 & 142 & 40 \\
\hline March 2020 $(n)$ & 72 & 16 & 23 & 105 & 38 \\
\hline Difference, \% & -13.3 & -23.3 & +53.3 & -26.1 & -5 \\
\hline April 2019 $(n)$ & 71 & 30 & 22 & 157 & 35 \\
\hline April 2020 $(n)$ & 53 & 17 & -13.6 & -48.4 & 16 \\
\hline Difference, \% & -25.4 & -43.3 & 37 & 299 & -54.3 \\
\hline Total 2019 $(n)$ & 154 & 51 & 42 & 186 & 75 \\
\hline Total 2020 $(n)$ & 125 & 33 & +13.5 & -37.8 & 54 \\
\hline Difference, \% & -18.8 & -35.3 & & -28 \\
\hline
\end{tabular}


1 March and 30 April 2020 and between 1 March and 30 April 2019. Collectively, during the COVID-19 period, the five TIA outpatient clinics of the North West London region received 440 referrals compared with 616 referrals received between 1 March and 30 April 2019. This was associated with a fall in the number of the referrals by $28.6 \%$. Of note, when we compared April 2020 with April 2019, the number of the referrals declined steeply by $40.1 \%$. We also documented a $15.6 \%$ decrease in the number of referrals received across the North West London region in March 2020 in contrast to March 2019, respectively 254 and 301. During the COVID-19 period Northwick Park Hospital and Chelsea and Westminster Hospital showed the greatest decline in the number of referrals to their TIA services, respectively $37.8 \%$ and 35.3\%. The TIA service at Hillingdon Hospital was the only centre in North West London that demonstrated an overall increased number of referrals compared with same period in 2019 . However, there was a $13.6 \%$ reduction in the number of patients referred to the TIA clinic at Hillingdon Hospital in April 2020 compared with April 2019.

\section{DISCUSSION}

In this multicentre analysis we showed an overall reduction, between $18.8 \%$ and $37.8 \%$, in the number of patients referred with suspected TIA to the specialised rapid access outpatient clinics in the North West London region during the COVID-19 pandemic.

To the authors' knowledge, this is the first multicentre report to document a significant decline in the referrals of patients with milder stroke symptoms to the TIA clinics of the same region during the COVID-19 pandemic. The COVID-19 outbreak is having implications on stroke services in all parts of the world in terms of redeployment of stroke staff, reallocation of the stroke beds for COVID-19 patients and reduction of urgent interventions such as endovascular treatment and intravenous thrombolysis. ${ }^{10}$ On the other hand, this pandemic has also largely impacted indirectly on the stroke care also in terms of sharp decline in acute stroke admissions. ${ }^{41}$

Our results highlight that patients, especially those with milder stroke symptoms, may have intentionally avoided hospitals during the COVID-19 pandemic. Due to fears of infection, patients may now neglect milder stroke symptoms of a possible TIA to the point that they do not present to their local GPs in the primary-care or EDs while the reported incidence rate of more severe cerebrovascular events, such as ischaemic stroke due to large vessel occlusion, remained stable during the COVID-19 pandemic as these more severe symptoms are less likely to be ignored by patients or family members. ${ }^{11}$ Clinicians as well as patients and their family should be aware of the importance of early recognition and treatment of even milder stroke symptoms even in these difficult times.

We are aware that our study has several limitations. Our study is limited by the retrospective design and our results reflect the trend in number of referrals to TIA clinics in a determined area which may not be generalised to all international healthcare practices some of which evaluate TIAs as inpatients. Finally, our findings are descriptive in nature and potential causes or confounders for the decreased number of referrals received by the TIA clinics during the COVID-19 pandemic were not explored (eg, GPs are performing a more careful and thorough risk/benefit assessment of the appropriateness of their referral that is, TIA vs mimics, given the risk of COVID-19 exposure).

\section{SUMMARY/CONCLUSIONS}

In conclusion, we believe that our multicentre study provides further evidence of the impact of the COVID-19 pandemic on acute stroke services. Future studies and data acquisition from larger studies representing multiple populations are needed to confirm our findings and to better characterise the incidence of cerebrovascular disease during the COVID-19 pandemic.

\section{Author affiliations}

${ }^{1}$ Division of Brain Sciences, Imperial College London, London, UK

${ }^{2}$ Department of Stroke and Neuroscience, Charing Cross Hospital, Imperial College London NHS Healthcare Trust, London, United Kingdom

${ }^{3}$ Stroke Department, West Middlesex University Hospital, Isleworth, UK

${ }^{4}$ Stroke Department, Northwick Park Hospital, Harrow, UK

${ }^{5}$ Stroke Department, Chelsea and Westminster Healthcare NHS Trust, London, UK

${ }^{6}$ Stroke Department, Hillingdon Hospital, Uxbridge, UK

\section{Twitter Lucio D'Anna @luciodanna2}

Acknowledgements We would like to thank the entire medical and nursing staff of the TIA clinics at Charing Cross Hospital, Chelsea and Westminster Hospital, Hillingdon Hospital, Northwick Park Hospital and West Middlesex Hospital for their contribution.

Contributors LD: study concept, statistical analysis, drafting and critical revision of manuscript. AS: data collection, critical revision of manuscript. RB: data collection, critical revision of manuscript. SE: data collection, critical revision of manuscript. A0: data collection, critical revision of manuscript. RS: data collection, critical revision of manuscript. RR: data collection, critical revision of manuscript. JJ: data collection, critical revision of manuscript. SB: data collection, critical revision of manuscript. EV: study concept, drafting and critical revision of manuscript.

Funding The authors have not declared a specific grant for this research from any funding agency in the public, commercial or not-for-profit sectors.

Competing interests None declared.

Patient and public involvement Patients and/or the public were not involved in the design, or conduct, or reporting, or dissemination plans of this research.

Patient consent for publication Not required.

Ethics approval No ethical approval was required for this type of research. In addition, no individual patient data were collected. Informed consent was not a legal requirement as the research was carried out using data collected as part of routine care and any researchers outside of the direct care team only had access to anonymised data.

Provenance and peer review Not commissioned; externally peer reviewed.

Data availability statement Data are available upon reasonable request. The data that support the findings of this study are available from the corresponding author on reasonable request.

Open access This is an open access article distributed in accordance with the Creative Commons Attribution Non Commercial (CC BY-NC 4.0) license, which permits others to distribute, remix, adapt, build upon this work non-commercially, and license their derivative works on different terms, provided the original work is 
properly cited, appropriate credit is given, any changes made indicated, and the use is non-commercial. See: http://creativecommons.org/licenses/by-nc/4.0/.

\section{ORCID iD}

Lucio D'Anna http://orcid.org/0000-0002-6794-3850

\section{REFERENCES}

1 Lavallée PC, Meseguer E, Abboud H, et al. A transient ischaemic attack clinic with round-the-clock access (SOS-TIA): feasibility and effects. Lancet Neurol 2007;6:953-60.

2 Rothwell PM, Giles MF, Chandratheva A, et al. Effect of urgent treatment of transient ischaemic attack and minor stroke on early recurrent stroke (express study): a prospective population-based sequential comparison. Lancet 2007;370:1432-42.

3 Cancelli I, Janes F, Gigli GL, et al. Incidence of transient ischemic attack and early stroke risk: validation of the ABCD2 score in an Italian population-based study. Stroke 2011;42:2751-7.

4 Saban M, Reznik A, Shachar T, et al. Reduction in stroke patients' referral to the ED in the COVID-19 era: A four-year comparative study. medRxiv 2020.
5 Hartnett KP, Kite-Powell A, DeVies J, et al. Impact of the COVID-19 Pandemic on Emergency Department Visits - United States, January 1, 2019-May 30, 2020. MMWR Morb Mortal Wkly Rep 2020;69:699-704.

6 Wong LE, PhD MD; , Hawkins JE, et al. Where are all the patients? addressing Covid-19 fear to encourage sick patients to seek emergency care. NEJM Catal 2020.

7 De Filippo O, D'Ascenzo F, Angelini F, et al. Reduced rate of hospital admissions for ACS during Covid-19 outbreak in northern Italy. $N$ Engl J Med 2020;383:88-9.

8 Brainin M. Stroke care and the COVID19 pandemic words from our president, 2020.

9 Teo K-C, Leung WCY, Wong Y-K, et al. Delays in stroke onset to hospital arrival time during COVID-19. Stroke 2020;51:2228-31.

10 Markus HS, Brainin M. EXPRESS: COVID-19 and Stroke - A Global World Stroke Organisation perspective. Int. J. Stroke 2020;0:174749302092347.

11 Siegler JE, Heslin ME, Thau L, et al. Falling stroke rates during COVID-19 pandemic at a comprehensive stroke center. J Stroke Cerebrovasc Dis 2020;29:104953. 